\title{
Observational operators for dual polarimetric radars in variational data assimilation systems (PolRad VAR v1.0)
}

\author{
Takuya Kawabata ${ }^{1}$, Thomas Schwitalla ${ }^{2}$, Ahoro Adachi ${ }^{1}$, Hans-Stefan Bauer ${ }^{2}$, Volker Wulfmeyer ${ }^{2}$, \\ Nobuhiro Nagumo ${ }^{1}$, and Hiroshi Yamauchi ${ }^{3}$ \\ ${ }^{1}$ Meteorological Research Institute, Japan Meteorological Agency, Tsukuba, 3050052, Japan \\ ${ }^{2}$ Institute of Physics and Meteorology, University of Hohenheim, 70599 Stuttgart, Germany \\ ${ }^{3}$ Japan Meteorological Agency, Tokyo, 1008122, Japan
}

Correspondence: Takuya Kawabata (tkawabat@mri-jma.go.jp)

Received: 16 February 2018 - Discussion started: 23 March 2018

Revised: 23 May 2018 - Accepted: 8 June 2018 - Published: 22 June 2018

\begin{abstract}
We implemented two observational operators for dual polarimetric radars in two variational data assimilation systems: WRF Var, the Weather Research and Forecasting Model variational data assimilation system, and NHM4DVAR, the nonhydrostatic variational data assimilation system for the Japan Meteorological Agency nonhydrostatic model. The operators consist of a space interpolator, two types of variable converters, and their linearized and transposed (adjoint) operators. The space interpolator takes account of the effects of radar-beam broadening in both the vertical and horizontal directions and climatological beam bending. The first variable converter emulates polarimetric parameters with model prognostic variables and includes attenuation effects, and the second one derives rainwater content from the observed polarimetric parameter (specific differential phase). We developed linearized and adjoint operators for the space interpolator and variable converters and then assessed whether the linearity of the linearized operators and the accuracy of the adjoint operators were good enough for implementation in variational systems. The results of a simple assimilation experiment showed good agreement between assimilation results and observations with respect to reflectivity and specific differential phase but not with respect to differential reflectivity.
\end{abstract}

\section{Introduction}

The Weather Research and Forecasting Model (WRF; Skamarock et al., 2008) is a widely used numerical weather model that was developed as a community model, and WRF Var, its data assimilation system (Barker et al., 2012), provides initial conditions for the model. NHM-4DVAR is a nonhydrostatic 4D-Var system for the Japan Meteorological Agency nonhydrostatic model (JMANHM; Saito, 2012) that functions at storm scale (Kawabata et al., 2007, 2014a). Many remote sensing data are available for NHM-4DVAR, such as the following: slant total delay, zenith total delay, and precipitable water vapor observed by global navigation satellite systems (GNSS; Kawabata et al., 2013); conventional radar data, including directly assimilated reflectivity data (Kawabata et al., 2011); and Doppler lidar data (Kawabata et al., 2014b). Because data assimilation associates observations with model fields, to make use of advanced observations, data assimilation methods need to be continuously developed and implemented into variational data assimilation systems.

Observations obtained by dual polarimetric radars are utilized by operational systems at many meteorological and hydrological operation centers (e.g., in the United States, France, Germany, and Japan) to improve the accuracy of quantitative precipitation estimation (QPE). These radars provide polarimetric parameters, including the horizontally polarized reflectivity factor $\left(Z_{\mathrm{H}}\right)$, the vertically polarized reflectivity factor $\left(Z_{\mathrm{V}}\right)$, differential reflectivity $\left(Z_{\mathrm{DR}}\right)$, and the specific differential phase $\left(K_{\mathrm{DP}}\right)$. Many QPE methods that use these parameters have been proposed (e.g., Jameson, 
1991; Jameson and Caylor, 1994; Ryzhkov and Zrnić, 1995; Anagnostou et al., 2008; Kim et al., 2010; Ryzhkov et al., 2014; Adachi et al., 2015). Because QPE methods using dual polarimetric radar parameters are expected to be better than methods using single polarization radar data, we developed assimilation methods for dual polarimetric radar observations for both WRF Var and NHM-4DVAR. The objective of our study was thus to improve QPE, which was discussed in Bauer et al. (2015) in the context of data assimilation with high resolution and a rapid update cycle, and quantitative rainfall forecasts (QPF) through the use of better analysis fields obtained by the assimilation of dual polarimetric radar observations.

We chose an emulator (Zhang et al., 2001) and an estimator (Bringi and Chandrasekar, 2001) to use as forward operators after evaluating their accuracy (Kawabata et al., 2018). In addition, because both WRF Var and NHM-4DVAR consider only perturbations to rainwater in their tangent and adjoint models, our operators also deal only with rainwater and exclude ice particles. Although both the emulator of Jung et al. (2008a, b) and the estimator of Yokota et al. (2016) have been used previously as observational operators in ensemble Kalman filter data assimilation systems, to our knowledge, our study is their first implementation in variational assimilation systems. We refer to the current version of the operators as PolRad VAR v1.0.

The first author has mainly contributed to the WRF Var version of these operators developed over the rapid-update WRF 3D-Var system at the University of Hohenheim, Germany (see, e.g., Schwitalla et al., 2011; Schwitalla and Wulfmeyer, 2014; Bauer et al., 2015) and then to the version for NHM-4DVAR at the Meteorological Research Institute, Japan Meteorological Agency.

The scope of this paper is to provide the technical information on the observational operators and some evaluation results to help users understand the theoretical and practical aspects of the operators. The forward operators (space interpolator and variable converters) and their linearized (tangent linear) and transposed (adjoint) operators are described in Sect. 2. Section 3 describes the setup options of the observational operators, Sect. 4 presents verification and assimilation test results, and Sect. 5 is a summary.

\section{Observational operators}

In variational data assimilation systems, a cost function is defined and then iteratively minimized until its gradient becomes zero. The cost function and its gradient are defined as

$$
\begin{aligned}
& J(\mathbf{x})=\frac{1}{2}\left(\mathbf{x}-\mathbf{x}^{b}\right)^{\mathrm{T}} \mathbf{B}^{-1}\left(\mathbf{x}-\mathbf{x}^{b}\right) \\
& +\frac{1}{2}(H(\mathbf{x})-\mathbf{y})^{\mathrm{T}} \mathbf{R}^{-1}(H(\mathbf{x})-\mathbf{y}),
\end{aligned}
$$

$\nabla J(\mathbf{x})=\mathbf{B}^{-1}\left(\mathbf{x}-\mathbf{x}^{b}\right)+\mathbf{H}^{\mathrm{T}} \mathbf{R}^{-1}(H(\mathbf{x})-\mathbf{y})$,

where $\mathrm{T}$ denotes the transpose of a matrix; $\mathbf{x}, \mathbf{x}^{b}$, and $\mathbf{y}$ are model fields, first-guess fields, and observations, respectively, and $H(\mathbf{x}), \mathbf{H}$, and $\mathbf{H}^{T}$ represent the observational operators, their linearized operators (tangent linear), and their transposed (adjoint) operators, respectively. The observational operators work as variable converters $\left(H_{\mathrm{v}}\right)$ from model fields $\mathbf{x}$ to observational values related to observations $\mathbf{y}$ and as space interpolators $\left(H_{\mathrm{s}}\right)$ from model to observational space as follows:

$H(\mathbf{x})=H_{\mathrm{s}} H_{\mathrm{v}}(\mathbf{x})$.

We developed two types of variable converters, a single space interpolator, and their tangent linear and adjoint operators. Both WRF Var and NHM-4DVAR consider only perturbation to the mixing ratio of the rainwater and not to its number density in the tangent linear and adjoint models. However, in the tangent and adjoint operators described here (Sect. 2.2), the non-perturbed number density of rainwater is included. This variable is initialized to zero at the beginning or end of the operators, and this effect is directly considered in the cost functions of WRF Var and NHM-4DVAR, whereas its gradient is indirectly considered through perturbations of the mixing ratios of rainwater, water vapor, and other variables like temperature and pressure.

It is recommended that users of WRF Var run the system with CLOUD_CV (required) and the CV7 (optional) switches. The former adds the mixing ratios of rainwater to the default control variable set (Wang et al., 2013), and the latter replaces the control variables of stream function and velocity potential with momentum control variables to improve the performance of WRF simulations at high horizontal resolution (Sun et al., 2016). With these selections, the control variables in WRF Var are almost the same as those in NHM-4DVAR (Kawabata et al., 2011).

\subsection{Variable converters}

\subsubsection{Model variables to polarimetric parameters (FIT)}

Among the many numerical precipitation scheme options (e.g., single-moment scheme, large-scale condensation scheme) for WRF and JMANHM, we chose doublemoment schemes (WRF, Morrison et al., 2009; JMANHM, Hashimoto, 2008) for our observational operators because such schemes predict both the number density $\left(N_{\mathrm{r}} ; \mathrm{m}^{-3}\right)$ and the mixing ratio $\left(Q_{\mathrm{r}} ; \mathrm{kg} \mathrm{kg}^{-1}\right)$ of rainwater, whereas singlemoment schemes predict only $Q_{\mathrm{r}}$. Therefore, two of three unknown parameters in the drop size distribution (DSD) function are detected by the schemes. Following Morrison et al. (2009), the DSD function is given by

$N(D)=N_{0} D^{\mu} \exp (-\Lambda D)$, 
where $D(\mathrm{~mm})$ is the raindrop diameter, $N_{0}\left(\mathrm{~mm}^{-1} \mathrm{~m}^{-3}\right)$ is the intercept parameter, $\mu$ is the shape parameter, and $\Lambda$ $\left(\mathrm{mm}^{-1}\right)$ is the slope parameter. $\Lambda$ is given by

$\Lambda=\left(\frac{\pi \rho_{\mathrm{w}} N_{\mathrm{r}}}{10^{3} \rho_{\mathrm{a}} Q_{\mathrm{r}}}\right)^{\frac{1}{3}}$,

where $\rho_{\mathrm{w}}$ is the density of water ( $997 \mathrm{~kg} \mathrm{~m}^{-3}$ in this study) and $\rho_{\mathrm{a}}$ is air density $\left(\mathrm{kg} \mathrm{m}^{-3}\right)$, a model diagnostic variable. $\rho_{\mathrm{a}}$ and $N_{0}$ are given by

$\rho_{\mathrm{a}}=\frac{p}{R T\left(1+0.61 q_{\mathrm{v}}\right)}$,

$N_{0}=N_{\mathrm{r}} \Lambda$,

where $p$ is atmospheric pressure $(\mathrm{Pa}), R$ is the gas constant, $T$ is temperature $(\mathrm{K})$, and $q_{\mathrm{v}}$ is the mixing ratio of water vapor $\left(\mathrm{kg} \mathrm{kg}^{-1}\right)$.

In our study, the remaining unknown parameter $\mu$ is fixed at zero, and $N(D)$ is based on bulk sampling; the minimum and maximum values of $D$ are set to 0.05 and $5 \mathrm{~mm}$, respectively.

Because in the rainwater prognostic variables raindrops are assumed to be spherical in both WRF and JMANHM, we introduce the axis ratio of a raindrop, which is polynomial to $D$ (Brandes et al., 2002, 2005), as follows:

$$
\begin{aligned}
r= & 0.9951+2.51 \times 10^{-2} D-3.644 \times 10^{-2} D^{2} \\
& +5.303 \times 10^{-3} D^{3}-2.492 \times 10^{-4} D^{4} .
\end{aligned}
$$

Radar observations are derived from measurements of the scattering of electromagnetic waves by raindrops. The first converter is based on fitting functions that relate equivolume diameters $D$ to scattering amplitude (Zhang et al., 2001). The backscattering amplitudes are represented by a powerlaw function as follows:

$$
\left|S_{\mathrm{h}, \mathrm{v}}(D)\right|=\alpha_{\mathrm{h}, \mathrm{v}} D^{\beta_{\mathrm{h}, \mathrm{v}}},
$$

where the coefficients $\alpha_{\mathrm{h}, \mathrm{v}}$ and $\beta_{\mathrm{h}, \mathrm{v}}$ are determined by fitting $D$ to the backscattering amplitudes $\left|S_{\mathrm{h}, \mathrm{v}}\right|$ calculated by the $T$-matrix method (Mishchenko et al., 1996). The difference between the horizontal and vertical forward-scattering amplitudes is defined as

$$
\operatorname{Re}\left(f_{\mathrm{h}}(D)-f_{\mathrm{v}}(D)\right)=\alpha_{\mathrm{k}} D^{\beta_{\mathrm{k}}},
$$

where $f_{\mathrm{h}}(D)$ and $f_{\mathrm{v}}(D)$ represent the horizontal and vertical forward-scattering amplitudes, and $\alpha_{\mathrm{k}}$ and $\beta_{\mathrm{k}}$ are determined by the fitting. Zhang et al. (2001) proposed fitting functions for S-band radars, and Kawabata et al. (2018) derived new fitting parameters for $\mathrm{C}$-band radars. Following Zhang et al. (2001), horizontal (H) and vertical (V) reflectivity factors are

$$
Z_{\mathrm{H}, \mathrm{V}}=\frac{4 \lambda^{4}}{\pi^{4}\left|K_{\mathrm{w}}\right|^{2}}\left(\alpha_{\mathrm{h}, \mathrm{v}}^{2} N_{0} \Lambda^{-\left(2 \beta_{\mathrm{h}, \mathrm{v}}+1\right)} \Gamma\left(2 \beta_{\mathrm{h}, \mathrm{v}}+1\right)\right),
$$

where $\lambda(\mathrm{m})$ is the radar wavelength, $K_{\mathrm{W}}$ is a constant, defined as $K_{\mathrm{W}}=(\varepsilon-1) /(\varepsilon+2)$, where $\varepsilon$ is the complex dielectric constant of water estimated as a function of wavelength and temperature (Sadiku, 1985), and $\Gamma$ represents the Gamma function. The horizontal reflectivity $Z_{\mathrm{H}}$ is converted to conventional reflectivity $Z_{\mathrm{h}}(\mathrm{dBZ})$ by

$Z_{\mathrm{h}}=10 \log _{10}\left(Z_{\mathrm{H}}\right)$,

and $Z_{\mathrm{DR}}(\mathrm{dB})$ is defined as

$Z_{\mathrm{DR}}=10 \log _{10}\left(Z_{\mathrm{H}} / Z_{\mathrm{v}}\right)=Z_{\mathrm{h}}-Z_{\mathrm{v}}$.

$K_{\mathrm{DP}}\left({ }^{\circ} \mathrm{km}^{-1}\right)$ is defined as

$K_{\mathrm{DP}}=\frac{180 \lambda}{\pi} N_{0} \alpha_{\mathrm{k}} \Lambda^{-\left(\beta_{\mathrm{k}}+1\right)} \Gamma\left(\beta_{\mathrm{k}}+1\right)$.

The attenuation effects are calculated as follows:

$$
\begin{aligned}
& Z_{\mathrm{h}}^{\text {att }}(x)=Z_{\mathrm{h}}(x)-2 \int_{0}^{x} A_{\mathrm{H}}(s) \mathrm{d} s, \\
& Z_{\mathrm{DR}}^{\text {att }}(x)=Z_{\mathrm{DR}}(x)-2 \int_{0}^{x} A_{\mathrm{DP}}(s) \mathrm{d} s,
\end{aligned}
$$

where $Z_{\mathrm{h}}^{\text {att }}$ and $Z_{\mathrm{DR}}^{\text {att }}$ represent attenuated $Z_{\mathrm{h}}$ and $Z_{\mathrm{DR}}$, respectively. $A_{\mathrm{H}}$ and $A_{\mathrm{DP}}$ are the specific attenuation $\left(\mathrm{dB} \mathrm{km}^{-1}\right)$ and the specific differential attenuation $\left(\mathrm{dB} \mathrm{km}^{-1}\right)$, respectively, defined as

$$
\begin{aligned}
& A_{\mathrm{H}}=\alpha_{\mathrm{H}} K_{\mathrm{DP}}^{\beta_{\mathrm{H}}}, \\
& A_{\mathrm{DP}}=\alpha_{\mathrm{d}} K_{\mathrm{DP}}^{\beta_{\mathrm{d}}} .
\end{aligned}
$$

The values of the coefficients $\alpha_{\mathrm{h}}, \alpha_{\mathrm{v}}, \alpha_{\mathrm{k}}, \alpha_{\mathrm{H}}$, and $\alpha_{\mathrm{d}}$ and $\beta_{\mathrm{h}}$, $\beta_{\mathrm{v}}, \beta_{\mathrm{k}}, \beta_{\mathrm{H}}$, and $\beta_{\mathrm{d}}$ for C-band in these equations are listed in Table 1. Hereafter, this converter is called FIT.

FIT is also applicable for $\mathrm{X}$ - and S-bands by replacing the coefficients. Although we already prepared the coefficients for all bands in the source codes, the users should carefully investigate their validity.

\subsubsection{Observations of polarimetric parameters to model variables $(\mathrm{KD})$}

The second converter (hereafter KD) converts observed $K_{\mathrm{DP}}$ to rainwater content $\left(Q_{\text {rain }}\right)$ according to the following relation:

$Q_{\text {rain }}=3.565\left(\frac{K_{\mathrm{DP}}}{f}\right)^{0.77}$,

where $f(\mathrm{GHz})$ is the radar frequency and the power-law coefficients are from Bringi and Chandrasekar (2001). $Q_{\text {rain }}$ in the model is defined as $Q_{\text {rain }}=Q_{\mathrm{r}} \rho_{\mathrm{a}}\left(\mathrm{kg} \mathrm{m}^{-3}\right)$. Note that Eq. (19) is applicable not only for C-band but also X- and Sbands by putting their frequencies in $f$. Equations (4)-(19) 
Table 1. Values of the coefficients $\alpha$ and $\beta . \alpha_{\mathrm{h}, \mathrm{v}, \mathrm{k}}$ and $\beta_{\mathrm{h}, \mathrm{v}, \mathrm{k}}$ in Eqs. (9) and (10) and $\alpha_{\mathrm{H}, \mathrm{d}}$ in Eqs. (17) and (18) are from Kawabata et al. (2018), and $\beta_{\mathrm{H}, \mathrm{d}}$ in Eqs. (17) and (18) is from Bringi and Chandrasekar (2001).

\begin{tabular}{lrrrrr}
\hline Subscript & $\mathrm{h}$ & $\mathrm{v}$ & $\mathrm{k}$ & $\mathrm{H}$ & $\mathrm{d}$ \\
\hline$\alpha$ & 0.0016 & 0.0017 & $2.36 \times 10^{-5}$ & 0.073 & 0.013 \\
$\beta$ & 2.98 & 2.77 & 5.36 & 0.99 & 1.23 \\
\hline
\end{tabular}

follow Kawabata et al. (2018), and we put the equations with different order in this paper for reader convenience to understand the flow of implementations of the forward, tangent linear, and adjoint codes.

\subsection{Tangent linear and adjoint operators}

\subsubsection{Tangent linear and adjoint operators of FIT}

Because only $p, T$, and $q_{\mathrm{v}}$ are perturbed in WRF Var and NHM-4DVAR, the linearized form of Eq. (6) is

$$
\begin{aligned}
\Delta \rho_{\mathrm{a}} & =\frac{\Delta p}{R T\left(1+0.61 q_{\mathrm{v}}\right)}-\frac{p \Delta T}{R T^{2}\left(1+0.61 q_{\mathrm{v}}\right)} \\
& -\frac{0.61 p \Delta q_{\mathrm{v}}}{R T\left(1+0.61 q_{\mathrm{v}}\right)^{2}},
\end{aligned}
$$

and the perturbations of $\Lambda$ and $N_{0}$ are given as

$$
\begin{aligned}
& \Delta \Lambda=\frac{1}{3} \Lambda\left(-\Delta Q_{\mathrm{r}} Q_{\mathrm{r}}^{-1}-\Delta \rho_{\mathrm{a}} \rho_{\mathrm{a}}^{-1}\right), \\
& \Delta N_{0}=N_{\mathrm{r}} \Delta \Lambda,
\end{aligned}
$$

where $\Delta Q_{\mathrm{r}}$ and $\Delta N_{0}$ are perturbations of the mixing ratio and number density of rainwater, respectively. Note that the perturbation of $N_{\mathrm{r}}$ is not considered in the adjoint model (see Sect. 2). Thus, the perturbations of $Z_{\mathrm{H}, \mathrm{V}}, Z_{\mathrm{DR}}$, and $K_{\mathrm{DP}}$ are represented as follows.

$$
\begin{aligned}
& \Delta Z_{\mathrm{H}, \mathrm{v}}=\frac{4 \lambda^{4}}{\pi^{4}\left|K_{\mathrm{w}}\right|^{2}}\left(\alpha _ { \mathrm { h } , \mathrm { v } } ^ { 2 } \Gamma ( 2 \beta _ { \mathrm { h } , \mathrm { v } } + 1 ) \left(\Delta N_{0} \Lambda^{-\left(2 \beta_{\mathrm{h}, \mathrm{v}}+1\right)}\right.\right. \\
& \left.\left.\quad-\left(2 \beta_{\mathrm{h}, \mathrm{v}}+1\right) \Delta \Lambda N_{0} \Lambda^{-\left(2 \beta_{\mathrm{h}, \mathrm{v}}+2\right)}\right)\right) \\
& \Delta Z_{\mathrm{DR}}=\Delta Z_{\mathrm{h}}-\Delta Z_{\mathrm{v}} \\
& \Delta K_{\mathrm{DP}}=\frac{180 \lambda}{\pi} \alpha_{\mathrm{k}} \Gamma\left(\beta_{\mathrm{k}}+1\right)\left(\Delta N_{0} \Lambda^{-\left(\beta_{\mathrm{k}}+1\right)}\right. \\
& \left.\quad-\left(\beta_{\mathrm{k}}+1\right) \Delta \Lambda N_{0} \Lambda^{-\left(\beta_{\mathrm{k}}+2\right)}\right)
\end{aligned}
$$

Finally, the perturbations of $A_{\mathrm{H}}$ and $A_{\mathrm{DP}}$ are

$$
\begin{aligned}
& \Delta A_{\mathrm{H}}=\alpha_{\mathrm{H}} \beta_{\mathrm{H}} \Delta K_{\mathrm{DP}} K_{\mathrm{DP}}{ }^{\beta_{\mathrm{H}}-1}, \\
& \Delta A_{\mathrm{DP}}=\alpha_{\mathrm{d}} \beta_{\mathrm{d}} \Delta K_{\mathrm{DP}} K_{\mathrm{DP}}{ }^{\beta_{\mathrm{d}}-1} .
\end{aligned}
$$

The adjoint operators are represented by the transposed form of Eqs. (20)-(27), which is (tangent linear) ${ }^{\mathrm{T}}$. As an example, the adjoint of Eq. (27) is

$\Delta K_{\mathrm{DP}}=\Delta K_{\mathrm{DP}}+\alpha_{\mathrm{d}} \beta_{\mathrm{d}} K_{\mathrm{DP}}^{\beta_{\mathrm{d}}-1} \Delta A_{\mathrm{DP}}$.

\subsubsection{Tangent linear and adjoint operators of KD}

Because $K_{\text {DP }}$ in Eq. (19) is an observed value, it is not necessary to linearize the equation. However, the equation that relates $Q_{\text {rain }}$ to $Q_{\mathrm{r}}$ (Sect. 2.1.2) needs to be linearized as follows:

$\Delta Q_{\text {rain }}=\Delta Q_{\mathrm{r}} \rho_{\mathrm{a}}+Q_{\mathrm{r}} \Delta \rho_{\mathrm{a}}$

The transposed form of this equation is used for the adjoint model (see Sect. 2.2.1).

\subsection{Space interpolator}

Space interpolators in data assimilation systems map the model space to the observational space according to the representativeness of the observations. In the case of radar data, the effect of beam broadening stands for the representativeness, typically for a beam width of approximately $1.0^{\circ}$. The broadening is characterized by a Gaussian distribution orthogonal to the direction of the radar beam. Most previous studies (e.g., Seko et al., 2004; Wattrelot et al., 2014), except Zeng et al. (2016), consider only vertical beam broadening because numerical models have horizontal grid spacings of several kilometers, whereas they have vertical grid spacings in the lower troposphere of less than $1 \mathrm{~km}$. However, data assimilation systems must have sub-kilometer horizontal grid spacings as well (e.g., Kawabata et al., 2014a; Miyoshi et al., 2016) so that the space interpolators can take account of horizontal beam broadening. In addition, several phasedarray radars recently deployed in Japan have different beam widths in the vertical and horizontal directions. Our operator thus considers beam broadening in both the vertical and horizontal directions.

In addition, it is important for the space interpolator to include beam-bending effects, which depend on atmospheric conditions. In this study, the bending is determined by considering the climatological vertical gradient of the refractive index of the atmosphere in accordance with the effective Earth radius model (Doviak and Zrnić, 1993) following Haase and Crewell (2000), who showed statistically that the climatological refractive index is close to the actual refractive index at elevation angles higher than $1^{\circ}$ instead of by considering the actual atmospheric conditions, although Zeng et al. (2014) developed an excellent radar simulator that considers the actual refractivity of the atmosphere.

Remote sensing observations usually have higher spatial resolutions than model grid spacings. To avoid correlations of the observational errors in such high-resolution data, it is necessary either to thin the data or to use "super observations". In this study, we chose the super observation method, in which observations are averaged over each model grid cell. Super observation methods also have the advantage that they remove undesirable fluctuations associated with subgrid-scale phenomena, the assimilation of which makes the 
(a) Model grid

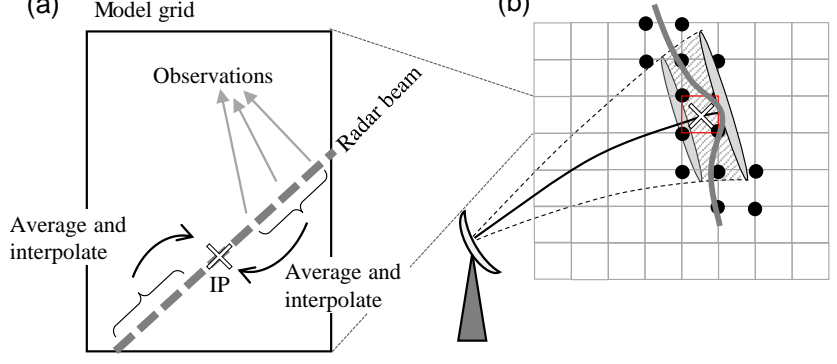

Figure 1. Schematic diagrams of (a) a super observation and (b) the space interpolator. Boxes represent model grid cells, and the red box indicates the grid cell in which the super observation is defined. The cross marks represent the interpolation point (IP). In panel (b), the grey curve indicates the Gaussian weights at various grid points (black circles), the solid black line shows the beam propagation, and the dashed lines illustrate beam broadening.

numerical model unnecessarily noisy (e.g., Seko et al., 2004; Zhang et al., 2009).

First, we calculated the path of the center of the radar beam in the model domain, including its elevation, azimuth, and bending angles (Fig. 1a). Once sufficient data are included within a model grid cell, they are averaged and mapped onto an interpolation point along the radar beam (IP in Fig. 1). This value at this point is a "super observation", and it is compared with the modeled value, which was interpolated by using Gaussian weights (Fig. 1b). Moreover, we also developed the tangent and adjoint codes of the space interpolator.

\section{Setup options}

The operators are controlled by the namelist ("namelist.polradar") as follows.

\&name_obs o_dir='/home/usr/datadir', o_stn(1)='OFT', o_stn(2) ='TUR', icnv=0/

Here, "o_dir" is the directory for the input observational data, "o_stn" indicates the station names of radar sites, where "max_stn", the number of names, is set in "da_setup_obs_structures_polradar.inc" in WRF Var and in "obs_dual_pol.f90:" in NHM-4DVAR, and "icnv" is a switch for the selection of the observational operator, where " 0 " and " 5 " mean FIT and KD, respectively.

In addition, a file that defines for each radar area where the beam is blocked by topography, named "beam_block_rate_\$\{radar_site $\}$.dat", must be supplied by the user. This file is made by another program and should be prepared before the assimilation.

\section{Results}

\subsection{Verification of the tangent linear and adjoint operators of FIT}

In this section, we examine the linearity of only the FIT variable converter; it is not necessary to examine the linearity of the KD converter because of the intrinsic linearity of Eq. (19). We evaluated the linearity of FIT by performing a Taylor expansion. If the original equation is given as

$\mathbf{y}=H(\mathbf{x})$,

then the linearized equation is defined as

$\delta \mathbf{y}=\mathbf{H} \delta \mathbf{x}$.

If the linear equation is derived with no errors, the following Taylor expansion of Eq. (31),

$\frac{|H(\mathbf{x}+\alpha \delta \mathbf{x})-H(\mathbf{x})|}{|\alpha||\mathbf{H} \delta \mathbf{x}|}=1+O(\alpha)$,

should be accurate within the rounding error of the computer. The results for $Z_{\mathrm{H}}, Z_{\mathrm{V}}$, and $K_{\mathrm{DP}}$ in Eqs. (11) and (14) are 1.00 when $\alpha$ is $10^{-7}$ to $10^{-15}$.

Regarding the adjoint operator, we evaluated the following equation:

$(\mathbf{H} \delta \mathbf{x})^{\mathrm{T}}(\mathbf{H} \delta \mathbf{x})=\delta \mathbf{x}^{\mathrm{T}}\left[\mathbf{H}^{\mathrm{T}}(\mathbf{H} \delta \mathbf{x})\right]$,

where the left-hand side of Eq. (33) is calculated using the tangent linear operator, and on the right-hand side, the output variables of the tangent linear operator are input into the adjoint operator. This equation must be accurate within the rounding error. In FIT, the difference between the left- and right-hand sides was $-8.215650382 \times 10^{-15}$, which we consider accurate enough.

\subsection{Actual data assimilation test}

We conducted two simple data assimilation tests. Observational errors of $Z_{\mathrm{h}}, Z_{\mathrm{DR}}, K_{\mathrm{DP}}$, and $Q_{\text {rain }}$, which were determined after the statistical examination (Kawabata et al., 2018), were $15.0 \mathrm{dBZ}$, which is the same as in Kawabata et al. (2011) at $2.0 \mathrm{~dB}, 4.0^{\circ} \mathrm{km}^{-1}$, and $4 \mathrm{~g} \mathrm{~m}^{-3}$, respectively. These errors are homogeneous in space, which means observational error covariances are diagonal.

The first one was done using NHM-4DVAR with actual radar data from the C-band dual polarimetric radar at the Meteorological Research Institute in Tsukuba, Japan (Yamauchi et al., 2012; Adachi et al., 2013). In this experiment, both radial velocity data and the polarimetric parameters of $Z_{\mathrm{H}}, Z_{\mathrm{DR}}$, and $K_{\mathrm{DP}}$ were assimilated in FIT, and radial velocity and $Q_{\text {rain }}$ derived from $K_{\mathrm{DP}}$ were assimilated in $\mathrm{KD}$. The assimilation window was from 21:00 to 21:05 UTC on 23 June 2014, a day on which intense hail fell in Tokyo, 
OBS

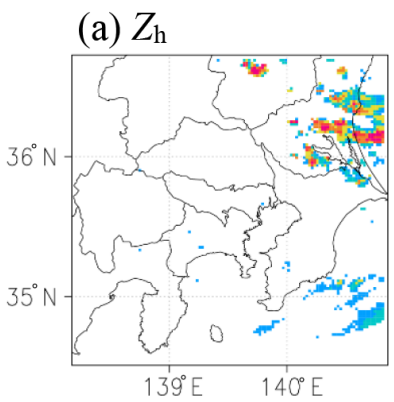

(e) $K_{\mathrm{DP}}$

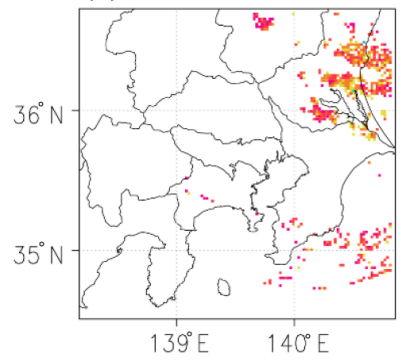

(i) $Z_{\mathrm{DR}}$

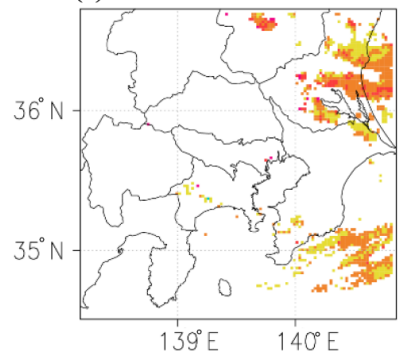

$\mathrm{KD}$

(b) $Z_{\mathrm{h}}$

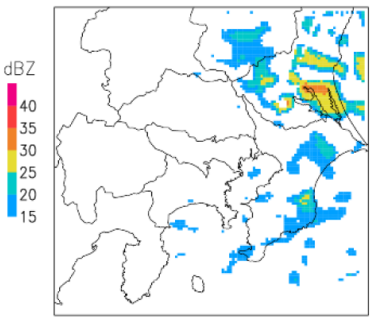

(c) $Z_{\mathrm{h}}$

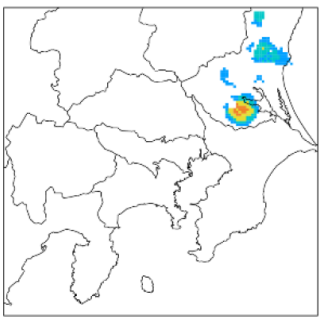

(d) $Z_{\mathrm{h}}$

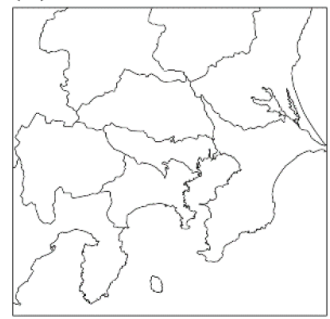

(f) $K_{\mathrm{DP}}$

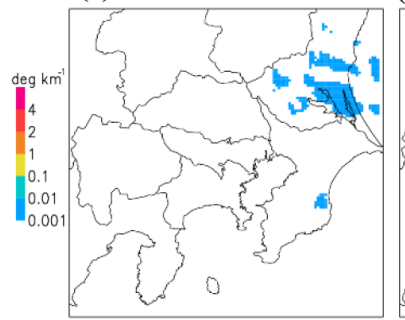

(g) $K_{\mathrm{DP}}$

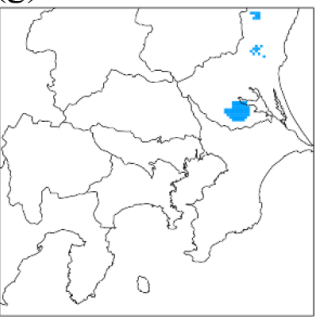

(h) $K_{\mathrm{DP}}$

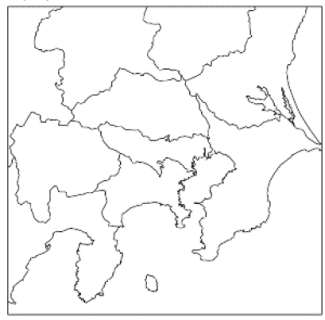

(k) $Z_{\mathrm{DR}}$

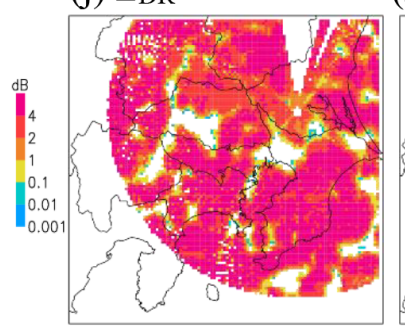

FG 
(a) $Z_{\mathrm{h}}$

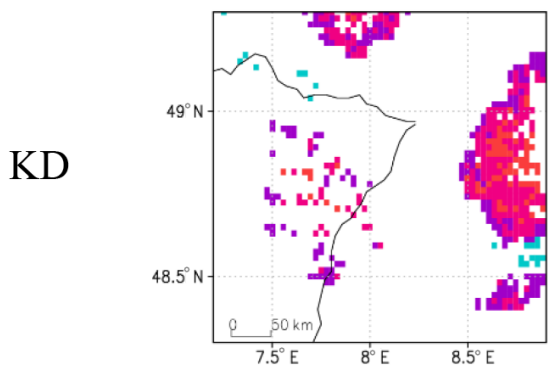

(d) $Z_{\mathrm{h}}$

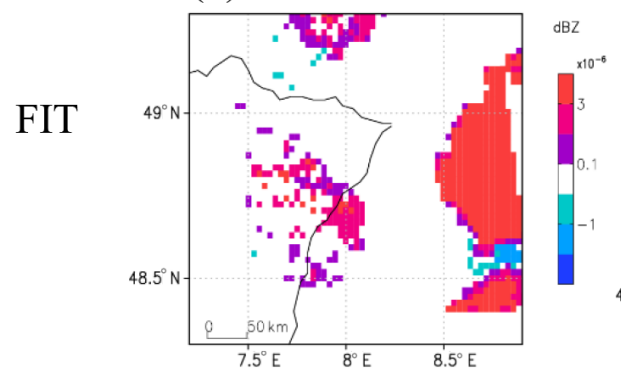

(b) $K_{\mathrm{DP}}$

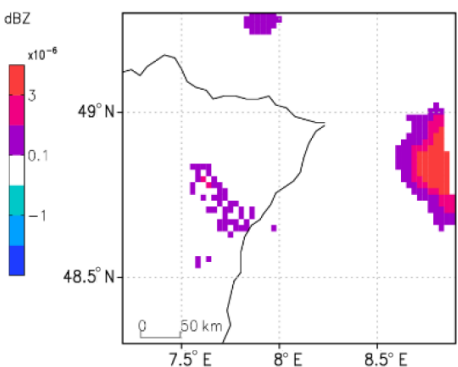

(e) $K_{\mathrm{DP}}$

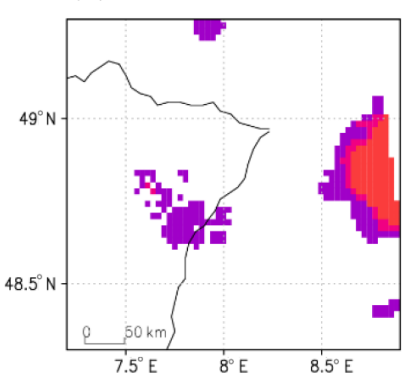

(c) $Z_{\mathrm{DR}}$

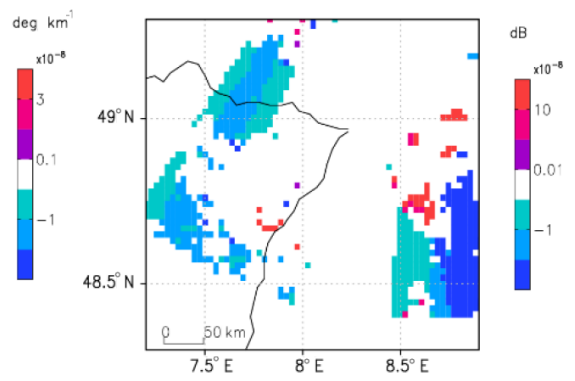

(f) $Z_{\mathrm{DR}}$
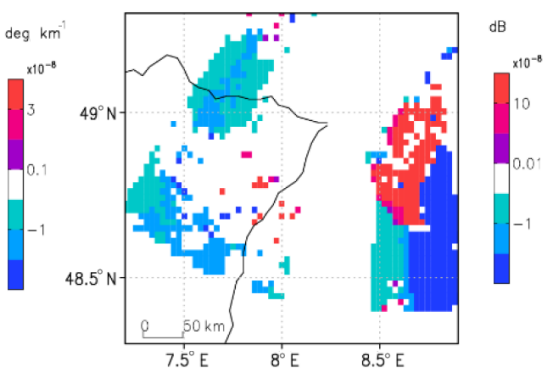

Figure 3. Horizontal distributions of differences in polarimetric parameters between assimilation results by KD and FIT with WRF 3D-Var and observations at 11:00 UTC on 14 August 2014.

of polarimetric parameters (Fig. 3), although quite small impacts are seen, similar patterns are recognized in both methods and larger impacts of $Z_{\mathrm{h}}$ and $Z_{\mathrm{DR}}$ were produced in FIT and $\mathrm{KD}$, respectively.

In both cases, the radial velocity data were assimilated with the same method as in Sun and Crook (1997).

\section{Summary}

We implemented two variable converters for polarimetric radars in the WRF variational data assimilation system (WRF Var) and the JMANHM data assimilation system (NHM-4DVAR). FIT simulates polarimetric parameters using a double-moment cloud microphysics scheme, and KD estimates rainwater contents with the observed specific differential phase. Both FIT and KD are applicable not only for C-band but also X- and S-bands. The advantage of FIT over $\mathrm{KD}$ is that it includes theoretically precise formulations for both the mixing ratio and number density of rainwater, as well as attenuation effects, whereas KD has advantages due to its linear formulation and small computational cost.

These operators work in conjunction with an advanced space interpolator, which considers (1) beam broadening in three dimensions, (2) different beam widths in the vertical and horizontal directions, and (3) the climatological beambending effect. The interpolator also simulated attenuation effects.
Tangent and adjoint operators of the two variable converters and the space interpolator were developed and implemented along with the forward operators. In a simple data assimilation experiment, we succeeded in assimilating actual polarimetric observations and obtained reasonable results with both the FIT and KD operators, except for $Z_{\mathrm{DR}}$. However, our results show a need for further improvements of the $K_{\mathrm{DP}}$ and $Z_{\mathrm{DR}}$ estimates. It would be possible to overcome the weaknesses of the $Z_{\mathrm{h}}$ distributions in FIT and FG through assimilation-forecast cycles and/or by adding other types of observation data, such as conventional observations, Doppler (water vapor) lidar data, and water vapor data observed by GNSS. Furthermore, it is necessary to improve quality controls (QCs) for polarimetric parameters, although the same QCs were applied as described in Kawabata et al. (2018) and the impact of axis ratio (Eq. 8) and observational errors on assimilations will be investigated, and it is necessary to estimate more appropriate observational errors (e.g., Wulfmeyer et al., 2016). These challenges would improve QPE and QPF with the current forms of the operators.

Code and data availability. Since PolRad VAR v1.0 for NHM4DVAR belongs to the Meteorological Research Institute of the Japan Meteorological Agency and is not publicly available, any researchers interested in the code are encouraged to contact the corresponding author and sign a contract for license to get the code. PolRad VAR v1.0 for WRF Var is currently being implemented into the community version of WRF Var and will be accessible at the WRF 
repository (http://www2.mmm.ucar.edu/wrf/users/downloads.html, last access: 19 June 2018) in the near future. Any researchers interested in the current form of the code can get it from the corresponding author via e-mail.

Competing interests. The authors declare that they have no conflict of interest.

Acknowledgements. We are grateful to the WRF development and support team. This study was partly supported by the Catchments As Organized System (CAOS) project funded by the German Research Foundation (FOR 1598), the Japanese Ministry of Education, Culture, Sports, Science and Technology "Advancement of meteorological and global environmental predictions utilizing observational Big Data" project, the Japan Science and Technology Agency (CREST) "Innovating Big Data Assimilation technology for revolutionizing very-short-range severe weather prediction" project (JPMJCR1312), and Grants-in-Aid for Scientific Research no. $16 \mathrm{H} 04054$ "Study of optimum perturbation methods for ensemble data assimilation" and no. 17H02962 "Study on uncertainties in convection initiations and developments using a particle filter" from the Japan Society for the Promotion of Science. We also express our sincere thanks to the reviewers, Juanzhen Sun and Soichiro Sugimoto, and the editor, Josef Koller, for their valuable contributions to this paper.

Edited by: Josef Koller

Reviewed by: Juanzhen Sun and Soichiro Sugimoto

\section{References}

Adachi, A., Kobayashi, T., Yamauchi, H., and Onogi, S.: Detection of potentially hazardous convective clouds with a dualpolarized C-band radar, Atmos. Meas. Tech., 6, 2741-2760, https://doi.org/10.5194/amt-6-2741-2013, 2013.

Adachi, A., Kobayashi, T., and Yamauchi, H.: Estimation of raindrop size distribution and rainfall rate from polarimetric radar measurements at attenuating frequency based on the selfconsistency principle, J. Meteorol. Soc. Jpn., 93, 359-388, 2015.

Anagnostou, M. N., Anagnostou, E. N., Vivekanandan, J., and Ogden, F. L.: Comparison of two raindrop size distribution retrieval algorithms for X-band dual polarization observations, J. Hydrometeorol., 9, 589-600, 2008.

Barker, D., Huang, X.-Y., Liu, Z., Auligné, T., Zhang, X., Rugg, S., Ajjaji, R., Bourgeois, A., Bray, J., Chen, Y., Demirtas, M., Guo, Y.-R., Henderson, T., Huang, W., Lin, H.-C., Michalakes, J., Rizvi, S., and Zhang, X.: The Weather Research and Forecasting Model's Community Variational/Ensemble Data Assimilation System: WRFDA, B. Am. Meteorol. Soc., 93, 831-843, 2012.

Bauer, H.-S., Schwitalla, T., Wulfmeyer, V., Bakhshaii, A., Ehret, U., Neuper, M., and Caumont, O.: Quantitative precipitation estimation based on high-resolution numerical weather prediction and data assimilation with WRF - a performance test, Tellus A, 67, 25047, https://doi.org/10.3402/tellusa.v67.25047, 2015.
Brandes, E. A., Zhang, G., and Vivekanandan, J.: Experiments in rainfall estimation with a polarimetric radar in a subtropical environment, J. Appl. Meteorol., 41, 674-685, 2002.

Brandes, E. A., Zhang, G., and Vivekanandan, J.: Corrigendum, J. Appl. Meteorol., 44, 186-186, 2005.

Bringi, V. N. and Chandrasekar, V.: Polarimetric Doppler weather radar-principle and application, Cambridge University Press, Cambridge, UK, 636 pp., 2001.

Doviak, R. J. and Zrnić, D. S.: Doppler radar and weather observations, Second edition, Dover publications, New York, USA, 562 pp., 1993.

Haase, G. and Crewell, S.: Simulation of radar reflectivities using a mesoscale weather forecast model, Water Resour. Res., 36, 2221-2231, 2000.

Hashimoto, A.: A double-moment cloud microphysical parameterization, Supplemental report at Numerical Prediction Division at Meteorological Agency, 54, 81-92, 2008 (in Japanese).

Helmert, K., Tracksdorf, P., Steinert, J., Werner, M., Frech, M., Rathmann, N., Hengstebeck, T., Mott, M., Schumann, S., and Mammen, T.: DWDs new radar network and postprocessing algorithm chain, Abstract of 8th European Conference on Radar in Meteorology and Hydrology, 15 September 2014, Garmisch-Partenkirchen, Germany, 6 pp., available at: http://www.pa.op.dlr.de/erad2014/programme/ ExtendedAbstracts/237_Helmert.pdf (last access: 19 June 2018), 2014.

Jameson, A. R.: A comparison of microwave techniques for measuring rainfall, J. Appl. Meteorol., 30, 32-54, 1991.

Jameson, A. R. and Caylor, I. J.: A new approach to estimating rainwater content by radar using propagation differential phase shift J. Appl. Meteorol. Clim., 11, 311-322, 1994.

Jung, Y., Zhang, G., and Xue, M.: Assimilation of simulated polarimetric radar data for a convective storm using the ensemble Kalman filter. Part I: observation operators for reflectivity and polarimetric variables, Mon. Weather Rev., 136, 2228-2245, 2008a.

Jung, Y., Xue, M., Zhang, G., and Straka, J. M.: Assimilation of simulated polarimetric radar data for a convective storm using the ensemble Kalman filter. Part II: impact of polarimetric data on storm analysis, Mon. Weather Rev., 136, 2246-2260, 2008 b.

Kawabata, T., Seko, H., Saito, K., Kuroda, T., Tamiya, K., Tsuyuki, T., Honda, Y., and Wakazuki, Y.: An Assimilation and Forecasting Experiment of the Nerima Heavy Rainfall with a Cloud-Resolving Nonhydrostatic 4-Dimensional Variational Data Assimilation System, J. Meteorol. Soc. Jpn., 85, 255-276, https://doi.org/10.2151/jmsj.85.255, 2007.

Kawabata, T., Kuroda, T., Seko, H., and Saito, K.: A cloudresolving 4D-Var assimilation experiment for a local heavy rainfall event in the Tokyo metropolitan area, Mon. Weather Rev., 139, 1911-1931, 2011.

Kawabata, T., Shoji, Y., Seko, H., and Saito, K.: A numerical study on a mesoscale convective system over a subtropical island with 4D-Var assimilation of GPS slant total delays, J. Meteorol. Soc. Jpn., 91, 705-721, 2013.

Kawabata, T., Ito, K., and Saito, K.: Recent Progress of the NHM4DVAR towards a Super-High Resolution Data Assimilation, SOLA, 10, 145-149, 2014a.

Kawabata, T., Iwai, H., Seko, H., Shoji, Y., Saito, K., Ishii, S., and Mizutani, K.: Cloud-Resolving 4D-Var Assimilation of Doppler 
Wind Lidar Data on a Meso-Gamma-Scale Convective System, Mon. Weather Rev., 142, 4484-449, 2014b.

Kawabata, T., Bauer, H.-S., Schwitalla, T., Wulfmeyer, V., and Adachi, A.: Evaluation of forward operators for polarimetric radars aiming for data assimilation, J. Meteorol. Soc. Jpn., 96A, 157-174, 2018

Kim, D. S., Maki, M., and Lee, D. I.: Retrieval of three-dimensional raindrop size distribution using X-band polarimetric radar data, J. Atmos. Ocean. Tech., 27, 1265-1285, 2010.

Mishchenko, M. I., Travis, L. D., and Mackowski, D. W.: T-matrix computations of light scattering by nonspherical particles: A review, J. Quant. Spectrosc. Ra., 55, 535-575, 1996.

Miyoshi, T., Kunii, M., Ruiz, J., Lien, G.-Y., Satoh, S., Ushio, T., Bessho, K., Seko, H., Tomita, H., and Ishikawa, Y.: "Big Data Assimilation" Revolutionizing Severe Weather Prediction, B. Am. Meteorol. Soc., 97, 1347-1354, 2016.

Morrison, H., Thompson, G., and Tatarskii, V.: Impact of cloud microphysics on the development of trailing stratiform precipitation in a simulated squall line: Comparison of one- and two-moment schemes, Mon. Weather Rev., 137, 991-1007, 2009.

Ryzhkov, A., Diederich, M., Zhang, P., and Simmer, C.: Potential utilization of specific attenuation for rainfall estimation, mitigation of partial beam blockage, and radar networking., J. Atmos. Ocean. Tech., 31, 599-619, 2014.

Ryzhkov, A. V. and Zrnić, D. S.: Comparison of dual-polarization radar estimators of rain, J. Atmos. Ocean. Tech., 12, 249-256, 1995.

Sadiku, M. N. O.: Refractive index of snow at microwave frequencies, Appl. Optics, 24, 572-575, 1985.

Saito, K.: The JMA nonhydrostatic model and its application to operation and research. Atmospheric Model Applications, edited by: Yucel, I., Intech, London, UK, 85-110, 2012.

Schwitalla, T. and Wulfmeyer, V.: Radar data assimilation experiments using the IPM WRF Rapid Update Cycle, Meteorol. Z., 23, 79-102, https://doi.org/10.1127/0941-2948/2014/0513, 2014.

Schwitalla, T., Bauer, H.-S., Wulfmeyer, V., and Aoshima, F.: Highresolution simu-lation over central Europe: Assimilation experiments with WRF 3DVAR during COPS IOP9c, Q. J. Roy. Meteor. Soc., 137, 156-175, https://doi.org/10.1002/qj.721, 2011.

Seko, H., Kawabata, T., Tsuyuki, T., Nakamura, H., Koizumi, K., and Iwabuchi, T.: Impacts of GPS-derived Water Vapor and Radial Wind Measured by Doppler Radar on Numerical Prediction of Precipitation, J. Meteorol. Soc. Jpn., 82, 473-489, 2004.

Skamarock, W., C., Klemp, J. B., Dudhia, J., Gill, D. O., Barker, D. M., Duda, M. G., Huang, X.-Y., Wang, W., and Powers, J. G.: A description of the advanced research WRF version 3, NCAR Tech. Note, National Center for Atmospheric Research, Colorado, USA, 2008.

Sun, J. and Crook, N. A.: Dynamical and microphysical retrieval from Doppler radar observations using a cloud model and its adjoint. Part I: Model development and simulated data experiments, J. Atmos. Sci., 54, 1642-1661, 1997.
Sun, J., Wang, H., Tong, W., Zhang, Y., Lin, C.-Y., and Xu, D.: Comparison of the Impacts of Momentum Control Variables on High-Resolution Variational Data Assimilation and Precipitation Forecasting, Mon. Weather Rev., 144, 149-169, 2016.

Wang, H., Sun, J., Fan, S., and Huang, X.-Y.: Indirect Assimilation of Radar Reflectivity with WRF 3D-Var and Its Impact on Prediction of Four Summertime Convective Events, J. Appl. Meteorol. Clim., 52, 889-902, 2013.

Wattrelot, E., Caumont, O., and Mahfouf, J.-F.: Operational Implementation of the 1D+3D-Var Assimilation Method of Radar Reflectivity Data in the AROME Model, Mon. Weather Rev., 142, 1852-1873, 2014.

Wulfmeyer, V., Muppa, S. K., Behrendt, A., Hammann, E., Späth, F., Sorbjan, Z., Turner, D. D., and Hardesty, R. M.: Determination of Convective Boundary Layer Entrainment Fluxes, Dissipation Rates, and the Molecular Destruction of Variances: Theoretical Description and a Strategy for Its Confirmation with a Novel Lidar System Synergy, J. Atmos. Sci., 73, 667-692, https://doi.org/10.1175/JAS-D-14-0392.1, 2016.

Yamauchi, H., Adachi, A., Suzuki, O., and Kobayashi, T.: Precipitation estimate of a heavy rain event using a C-band solid-state polarimetric radar, 7th European Conf. on Radar in Meteorology and Hydrology, 24-29 June 2012, Toulouse, France, available at: http://www.meteo.fr/cic/meetings/2012/ ERAD/extended_abs/SP_412_ext_abs.pdf (last access: 19 June 2018), 2012.

Yokota, S., Seko, H., Kunii, M., Yamauchi, H., and Niino, H.: The tornadic supercell on the Kanto Plain on 6 May 2012: Polarimetric radar and surface data assimilation with EnKF and ensemblebased sensitivity analysis, Mon. Weather Rev., 144, 3133-3157, 2016.

Zeng, Y., Blahak, U., Neuper, M., and Jerger, D.: Radar Beam Tracing Methods Based on Atmospheric Refractive Index, J. Atmos. Ocean. Tech., 31, 2650-2670, 2014.

Zeng, Y., Blahak, U., and Epperlein, D.: An Efficient Modular Volume Scanning Radar Forward Operator for NWP-models: Description and coupling to the COSMO-model, Q. J. Roy. Meteor. Soc., 142, 3234-3256, 2016.

Zhang, F., Weng, Y., Sippel, J. A., Meng, Z., and Bishop, C. H.: Cloud-resolving hurricane initialization and prediction through assimilation of Doppler radar observations with an ensemble Kalman filter, Mon. Weather Rev., 137, 2105-2125, 2009.

Zhang, G., Vivekanandan, J., and Brandes, E.: A method for estimating rain rate and drop size distribution from polarimetric radar measurements, IEEE T. Geosci. Remote, 39, 830-841, 2001. 